\title{
Molecular Phenotype Distinguishes Two Subsets of Gastric Low-Grade Mucosa-Associated Lymphoid Tissue Lymphomas
}

\author{
Elena Nardini, Simona Rizzi, Sylvie Ménard, and Andrea Balsari \\ Molecular Targeting Unit (EN, SR, SM), Department of Experimental Oncology, National Cancer Institute, and \\ Institute of Pathology (AB), University of Milan, Milan, Italy
}

\begin{abstract}
SUMMARY: Isotype switch recombination together with somatic mutation of immunoglobulin variable genes is indicative of B-cell maturation stage. Because aberrant isotype switch events occur in a proportion of gastric mucosa-associated lymphoid tissue (MALT) lymphomas, we tested whether gastric MALT lymphomas with or without aberrant rearrangements in the switch regions differ in B-cell maturation stage. Southern blot analysis of DNA from six gastric MALT lymphoma cases revealed the presence of aberrant isotype switch events in three cases. Somatic common mutations were present in all immunoglobulin variable heavy chain genes of the six cases, and homology with the closest germline ranged from $89.5 \%$ to $98.8 \%$. Replacement versus silent mutation ratio analysis of complementarity-determining regions and frameworks indicated the positive selective pressure of an antigen in four cases. In the remaining two cases, protein translated from the third complementarity-determining region suggested the selective pressure of an autoantigen. The three cases with aberrant isotype switch events showed no noncommon mutations, whereas two of three cases without evidence of aberrant isotype switch showed high levels of such mutations. Moreover the three cases with aberrant isotype switch, compared with the three cases without, showed an increased number of common mutations and of $\mathrm{N}$ segment additions. These data raise the possibility of two distinct subsets of gastric low-grade MALT lymphomas, one with aberrant isotype switch and no intraclonal diversification, and one with no aberrant isotype switch but with intraclonal diversification. The first subset may originate from a postgerminal center environment and the second from a germinal center. Alternatively, the first subset may derive from the second after maturation or after a transformation event that blocks the mutational process. (Lab Invest 2002, 82:535-541).
\end{abstract}

$M$ ucosa-associated lymphoid tissue (MALT) lymphoma cells, which are typically CD5 - CD10 and $\operatorname{lgM}^{+} \lg D^{-}$, are thought to derive from marginal zone $B$ cells and to arise at sites of chronic organspecific inflammation caused by autoimmunity or specific inflammation (Nakamura et al, 1998; Zucca et al, 1998). MALT Iymphoma of the stomach is acquired in the context of chronic lymphoid proliferation due to the presence of Helicobacter pylori and is characterized by centrocyte-like cells localized beneath the mucosal epithelium, potentially giving rise to lymphoepithelial lesions. The possibility of antigen-driven lymphomagenesis is strongly supported by the fact that gastric low-grade MALT Iymphomas can be cured with antibiotics that eradicate $H$. pylori (Bayerdorffer et al, 1995; Montalban et al, 1997; Roggero et al, 1995; Steinbach et al, 1999; Wotherspoon et al, 1991).

In B cells, which engage an antigen-driven immune response in the germinal center, isotype switch recombination together with somatic mutations in the

\section{Received July 26, 2001.}

Supported in part by Associazione Italiana Ricerca Cancro. Drs. Nardini and Rizzi contributed equally to this work.

Address reprint requests to: Prof. Andrea Balsari, Chair of Immunology, clo Department of Experimental Oncology, Molecular Targeting Unit, National Cancer Institute, Via Venezian 1, 20133 Milan, Italy. E-mail: balsari@istitutotumori.mi.it immunoglobulin variable genes contributes to the process of B-cell maturation. This maturation process can be divided into four stages. In the first stage, the B-cell progenitor undergoes no $V_{H} D J_{H}$ rearrangement or isotype switch. In the second stage, the naïve $B$ cell undergoes $V_{H} D J_{H}$ recombination but no $V_{H}$ gene mutation. In the third stage, the $B$ cell in the germinal center environment undergoes variable heavy chain $\left(V_{H}\right)$ gene mutation and isotype switch. Finally in the postgerminal center stage, the memory B cell or plasma cell accomplishes the mutational process and produces high-affinity antibodies (Kuppers et al, 1999). Analysis of $V_{H}$ gene mutations and isotype switch events in tumors of the B-cell lineage provides an estimate of B-cell developmental stage at which malignant transformation occurs (Matolcsy et al, 1997). We recently demonstrated that a proportion of $\operatorname{lgM}^{+}$gastric MALT lymphoma cells undergo aberrant isotype switch recombination and suggested that MALT without evidence of aberrant isotype switch recombination may originate from a less differentiated B cell (Nardini et al, 2000). Other studies of tumorderived rearranged $\mathrm{V}_{\mathrm{H}}$ genes demonstrated the presence of somatic mutations with evidence of intraclonal diversification, ie, noncommon mutations, in some cases (Du et al, 1996; Qin et al, 1995, 1997). The findings of aberrant isotype switch recombination and $\mathrm{V}_{\mathrm{H}}$ somatic mutations strongly suggest that direct 
antigen stimulation plays a role in clonal expansion of this tumor. Moreover, although the accumulation of somatic mutations in the $V_{H}$ genes indicates that the cell has been exposed to the hypermutation mechanism and therefore must have entered or passed through the germinal center (Bahler et al, 1991; Berek et al, 1991; Hummel et al, 1994; Levy et al, 1987; Rajewsky, 1996), the detection of intraclonal diversification allows discrimination between germinal center $B$ cells, which show noncommon mutations, and postgerminal center B cells, which do not (Kuppers et al, 1993).

To determine whether gastric low-grade MALT lymphomas with or without aberrant rearrangements in the switch regions differ in B-cell maturation stages, we investigated the $V_{H}$ gene mutational status. $V_{H}$ genes were sequenced and analyzed for the presence and nature of somatic mutations (common and noncommon) and for the presence of possible antigen selective pressure.

\section{Results}

\section{Detection of Rearrangements in Immunoglobulin Heavy} Chain (IgH) Switch Regions

Genomic DNA from six $\operatorname{lgM}^{+} / \mathrm{lgD}^{-}$gastric low-grade MALT lymphomas was analyzed by Southern blot for rearrangements in the $\mathrm{lgH}$ switch regions. Five pairs of probes (one pair for each isotype) that hybridize upstream (5') and downstream ( $\left.3^{\prime}\right)$ of each switch region were used for each case. Upstream and downstream switch probes detect the same restriction fragment for "germline" switch regions. "Productive" switch recombinations result in the generation of a restriction fragment detected by the $5^{\prime}$ switch $\mathrm{mu}\left(5^{\prime} \mathrm{S} \mu\right)$ probe and any $3^{\prime}$ switch probe. Finally "aberrant" switch recombinations generate restriction fragments uniquely detected by only one switch probe. Using different enzymatic digests (HindlII, Sphl, Bglll), three low-grade MALT lymphomas (nos. 1, 2, and 3) showed evidence of aberrant isotype switch recombination in the $S \mu$ region, and three cases (nos. 4,5 , and 6) showed no aberrant restriction fragments. Hybridizations with switch probes for other isotypes gave no aberrant restriction fragments. Representative hybridizations are shown in Figure 1.

\section{$V_{H}$ Gene Amplification and Analysis of Common Mutations}

$V_{H}$ genes were amplified from genomic DNA of each patient using different primer pairs ("Materials and Methods") that amplify the complete $\mathrm{V}_{\mathrm{H}}$ region or the region from framework (FR2) to the joining heavy chain region $\left(\mathrm{J}_{\mathrm{H}}\right)$. In all but one case (no. 4), a single monoclonal band was amplified (data not shown). Reaction products were cloned and sequenced, and multiple clones for each case were screened. Repeated $V_{H}$ gene sequences were identified in all cases. $V_{H}$ regions of all six low-grade MALT lymphomas revealed the correct frame with no stop codons.

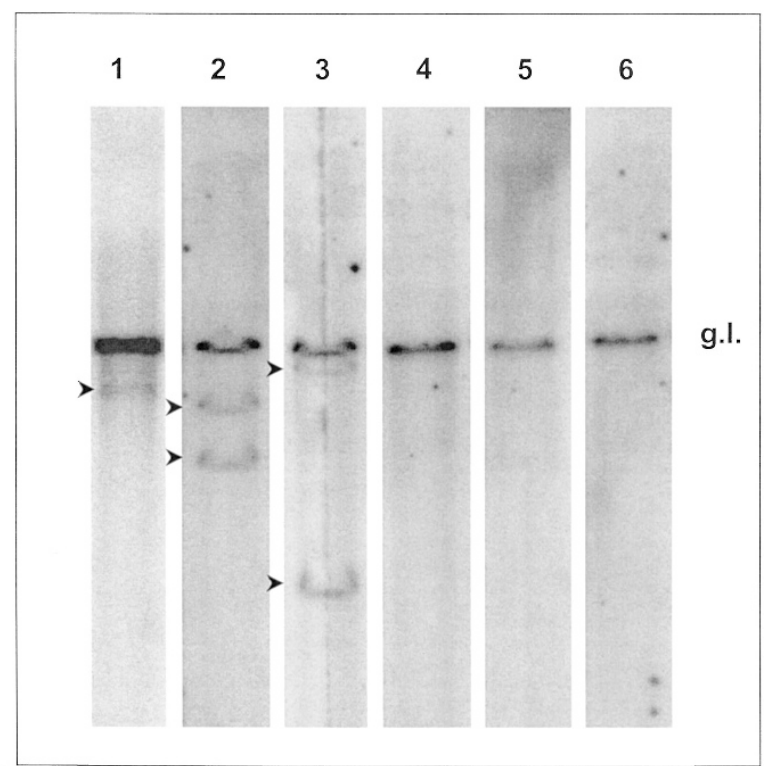

Figure 1.

Southern blot analysis of switch regions in six gastric low-grade mucosaassociated lymphoid tissue (MALT) lymphomas. Genomic DNA, digested with Sphl (cases 1 and 4) or HindIII (case 2, 3, 5, and 6), was electrophoresed, blotted, and probed sequentially with the $5^{\prime}$ switch $\mathrm{mu}\left(5^{\prime} \mathrm{S} \mu\right.$ ) probe. Aberrant isotype switch recombination fragments are indicated by an arrow and germline fragments by a "g.l."

Comparison of the $V_{H}$ sequences with the known germline genes revealed that one case (no. 2) belonged to the $\mathrm{V}_{\mathrm{H}} 3$ family, three cases (nos. 1, 5, and 6) to the $V_{\mathrm{H}} 4$ family, and one case (no. 3) to the $V_{\mathrm{H}} 5$ family; case 4 showed a biallelic $V_{H} D J_{H}$ rearrangement with $V_{H} 1$ on one allele and $V_{H} 4$ on the other allele (Table 1). Frequencies of common mutations were determined on the dominant or consensus $V_{H}$ sequence of each case. Somatic mutations were present in all $\mathrm{V}_{\mathrm{H}}$ sequences, and homology with the closest germline ranged from $89.5 \%$ to $98.8 \%$. The frequency of common mutations in patients 1,2 , and 3 was higher (mean $7.8 \%$ ) than in patients 4,5 and 6 (mean $2.4 \% ; p=0.05$; Table 2). The ratios of replacement to silent (R/S) mutations in the complementaritydetermining regions (CDRs) were higher than expected in four cases (nos. 1, 2, 4, and 5) and lower in the other two cases, whereas R/S mutations in FRs were lower than expected in all cases (Table 2).

\section{Analysis of $\mathrm{V}_{H}$ Region Noncommon Mutations}

In addition to common mutations, noncommon mutations above the estimated Taq error rate of approximately $0.2 \%$ were present in two cases (5 and 6$)$. For each patient, at least three independent clones were analyzed. Table 3 gives the number of analyzed sequences for each patient and the frequency of noncommon mutations ranging from $0.2 \%$ to $3.5 \%$. Figure 2 shows the sequences of four independent clones in case 5 and of three independent clones in case 6 with common and noncommon mutations. 
Table 1. Use of $V_{H}$, D, and $J_{H}$ Gene Segments by Six Gastric Low-Grade MALT Lymphomas

\begin{tabular}{|c|c|c|c|c|c|}
\hline Case & $\mathrm{V}_{\mathrm{H}}$ family & Closest germline & (\%) Homology & $\mathrm{D}$ gene & $J_{H}$ gene \\
\hline 1 & $V_{H} 4$ & $V_{H} 4-59$ & 95.9 & $N A^{b}$ & $J_{H} 4$ \\
\hline 2 & $V_{H} 3$ & $V_{H} 3-7$ & 89.5 & D3-16 & $J_{H} 4$ \\
\hline 3 & $V_{H} 5$ & $V_{H} 5-51$ & 91.2 & D5-12/D4-17 & $J_{H} 4$ \\
\hline \multirow[t]{2}{*}{4} & $V_{H} 1$ & $V_{H} 1-2$ & 100 & D6-19 & $J_{H} 4$ \\
\hline & $V_{H} 4$ & $V_{H} 4-59$ & 97.6 & D4-17 & $J_{H} 4$ \\
\hline $5^{a}$ & $V_{H} 4$ & $V_{H} 4-59$ & 96.3 & D4-17 & $J_{H} 4$ \\
\hline $6^{a}$ & $V_{H} 4$ & $V_{H} 4-59$ & 98.8 & D3-10 & $J_{H} 5$ \\
\hline
\end{tabular}

$V_{H}$, variable heavy chain; $D$, diversity; $J_{H}$, joining heavy chain; MALT, mucosa-associated lymphoid tissue; FR, framework.

${ }^{a}$ These cases were amplified from FR2 to $\mathrm{J}_{\mathrm{H}}$.

${ }^{b}$ Not assigned.

Table 2. Distribution of Common Mutations in the Six $\mathbf{V}_{\mathrm{H}}$ Genes

\begin{tabular}{|c|c|c|c|c|c|c|c|c|c|}
\hline \multirow[b]{2}{*}{ Case } & \multirow[b]{2}{*}{$\begin{array}{l}\text { Common mutations } \\
(\%)\end{array}$} & \multicolumn{4}{|c|}{ CDRs } & \multicolumn{4}{|c|}{ FRs } \\
\hline & & $\mathrm{R}$ & $S$ & $R / S$ & $\begin{array}{l}\text { Expected } \\
\text { R/S }\end{array}$ & $\mathrm{R}$ & $S$ & $\mathrm{R} / \mathrm{S}$ & $\begin{array}{c}\text { Expected } \\
\text { R/S }\end{array}$ \\
\hline 1 & $12(4.1)$ & 4 & 0 & & 4.55 & 4 & 4 & 1 & 2.63 \\
\hline 2 & $31(10.5)$ & 6 & 1 & 6 & 4.08 & 14 & 10 & 1.4 & 3.15 \\
\hline 3 & $26(8.8)$ & 6 & 2 & 3 & 3.83 & 12 & 6 & 2 & 2.95 \\
\hline $4^{a}$ & $7(2.4)$ & 2 & 0 & & 4.55 & 3 & 2 & 1.5 & 2.63 \\
\hline $5^{b}$ & $7(3.7)$ & 2 & 0 & $\infty$ & 4.55 & 3 & 2 & 1.5 & 2.63 \\
\hline $6^{b}$ & $2(1.2)$ & 0 & 0 & 0 & 4.55 & 1 & 1 & 1 & 2.63 \\
\hline
\end{tabular}

$R$, replacement; $S$, silent; $C D R$, complementarity-determining region; $F R$, framework; $V_{H}$, variable heavy chain; $J_{H}$, joining heavy chain.

${ }^{a}$ Analysis of the $\mathrm{V}_{\mathrm{H}} 4$ allele.

${ }^{b}$ Analysis of the FR2-J $J_{H}$ region.

Table 3. Aberrant Isotype Switch, Noncommon Mutations, Nümber of Analyzed Sequences, and Frequency of Noncommon Mutations in Six Cases of Gastric Low-Grade MALT Lymphoma

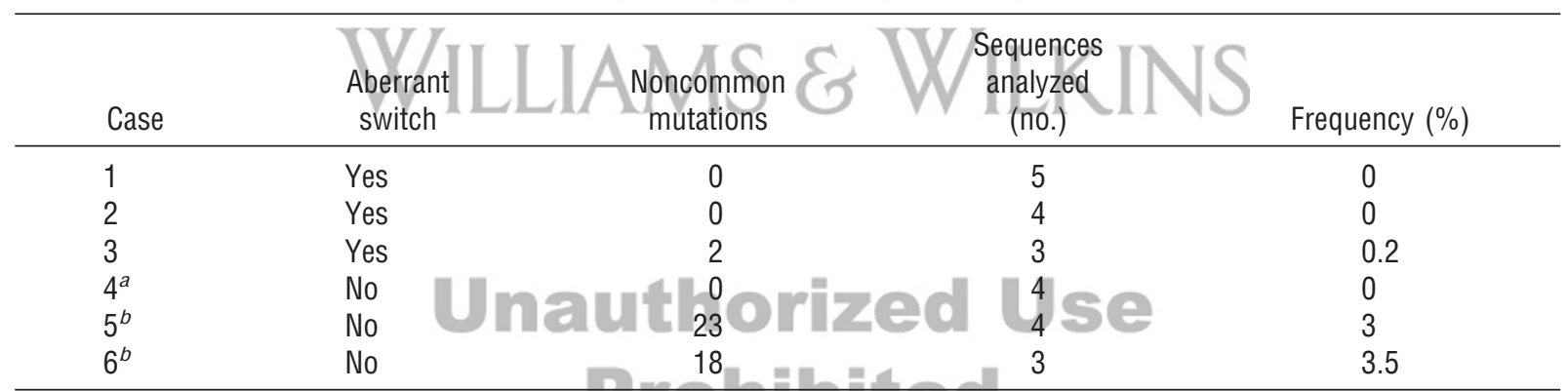

FR, framework; $V_{H}$, variable heavy chain.

${ }^{a}$ Analysis of the $V_{H} 4$ allele.

${ }^{b}$ Analysis of the FR2- $J_{H}$ region.

\section{CDR3 Region Analysis and Homology to Known Antibodies}

In all but one case (no. 1), the variable diversity (D) segments showed significant homology to one of the known germline D genes (Table 1). One case showed usage of the D4 family, one case showed usage of both D5 and D4, two cases shared usage of the D3 family, whereas case 4 showed D4 on one allele and D6 on the other. Cases from 1 to 5 used $\mathrm{J}_{\mathrm{H}} 4$ and case 6 used $\mathrm{J}_{\mathrm{H}} 5$.

For each patient, the consensus CDR3 nucleotide sequence was translated (Fig. 3). The mean length of the CDR3 ranged from 9 to 13 amino acids (mean 11) in MALT lymphomas with aberrant isotype switch and from 7 to 12 amino acids (mean 8.7) in lymphomas without aberrant isotype switch. Two $\mathrm{N}$ segments were added in the three cases with aberrant isotype switch, whereas only one $\mathrm{N}$ segment was added in the other three cases. Comparison of CDR3 amino acid sequences with GenBank databases revealed high homology to known antibodies in four cases. Case 3 showed $75 \%$ identity with an autoantibody from a patient with rheumatoid arthritis and case 6,72\% identity with an autoantibody from a patient with lupus. Cases 4 and 5 showed identity with an antibody isolated from a patient with Kawasaki disease $(77 \%$ and $83 \%$, respectively), whereas CDR3 from cases 1 and 2 showed no homology to any known antibody. 


\section{Case 5.}

vH4-59 TGGATCCGGCAGCCCCCAGGGAAGGGACTGGAGTGGATTGGG TATATCTATTACAGTGGGAGCACCAACTACAACCCCTCCCTCAAGAGT

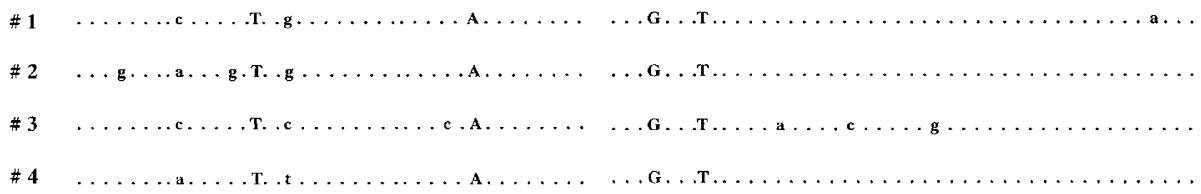

FWR3

VH4-59 CGAGTCACCATATCAGTAGACACGTCCAAGCCCTGAAGCTGAGCTCTGTGACCGCTGCGGACACGGCCGTGTATTACTGTGCGAGAGA

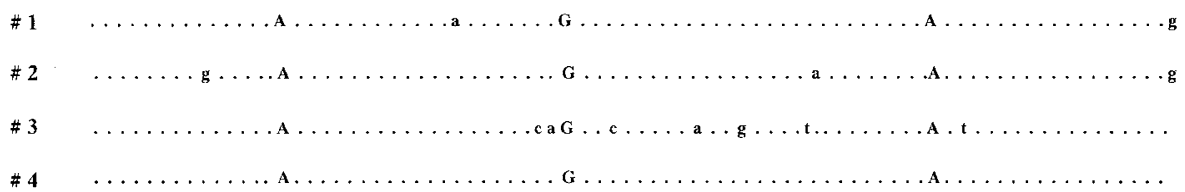

Case 6.

CDR2

vH4-59 TGGATCCGGCAGCCCCCAGGGAAGGGACTGGAGTGGATTGGG TATATCTATTACAGTGGGAGCACCAACTACAACCCCTCCCTCAAGAGT

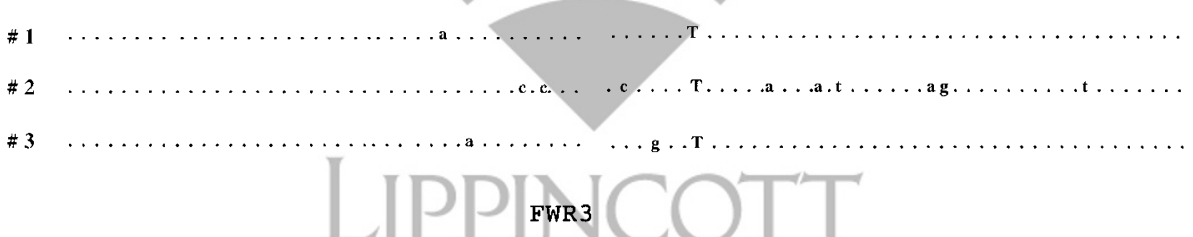

vH4-59 CGAGTCACCATATCAGTAGACACGTCCAAGCCCTGAAGCTGAGCTCTGTGACCGCTGCGGACACGGCCGTGTATTACTGTGCGAGAGA

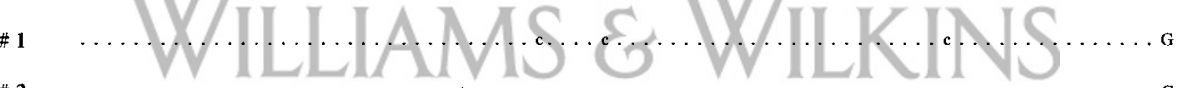

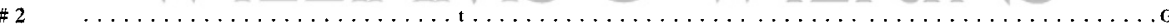

\#3

G

Figure 2.

$V_{H}$ gene intraclonal heterogeneity in two cases of gastric low-grade MALT lymphoma. Noncommon mutations are indicated in lower case and common mutations in upper case.

\section{Discussion}

In the present study, we investigated the relationship between aberrant isotype switch events and the extent and pattern of $\mathrm{V}_{\mathrm{H}}$ somatic mutations in six cases of gastric low-grade MALT lymphoma in an effort to define the maturation of the tumor precursor cell. Three of the low-grade MALT lymphomas showed evidence of aberrant isotype switch recombination, and our data indicate that such lymphomas have a different $V_{H}$ mutational status and therefore a different maturation stage as compared with MALT lymphomas lacking aberrant isotype switch.

The clonal $V_{H}$ genes of all six low-grade MALT lymphomas were potentially functional because no stop codons were present and the CDR3 sequences were in-frame. A biased usage of the $V_{H} 4$ family was observed. In addition we observed overuse of D4-17 and of $\mathrm{J}_{\mathrm{H}} 4$ segments. A predominant usage of the $\mathrm{J}_{\mathrm{H}} 4$ segment in gastric MALT lymphomas has been previously observed (Bertoni et al, 1997; Qin et al, 1995, 1997; Thiede et al, 1998), whereas an overuse of a specific $V_{H}$ family $\left(V_{H} 1-69\right)$, has been reported only in salivary gland MALT lymphomas (Miklos et al, 2000). This highly nonrandom repertoire suggests that B cells with particular heavy chains are preferentially selected for malignant transformation, presumably because of their enhanced ability to bind an antigen.

In our study, case 4 showed a biallelic $V_{H} D_{H}$ rearrangement $\left(\mathrm{V}_{\mathrm{H}} 1\right.$ and $\left.\mathrm{V}_{\mathrm{H}} 4\right)$, a phenomenon previously reported in cases of low-grade and high-grade MALT lymphomas (Hallas et al, 1998; Yumoto et al, 1999) and in B-cell chronic lymphocytic leukemia (Rassenti and Kipps, 1997).

In four cases the R/S ratios in the CDRs exceeded the expected values, whereas $R / S$ ratios in FRs 


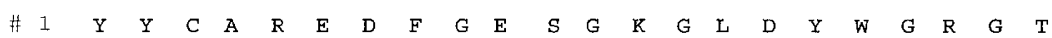

TAT TAC TGT GCG AGA GAA GAC T'TC GGI GAA TCC GGG NAG GGT TTG GAC TAC TGG GGC CGG GGA ACC

$\begin{array}{cllll}\text { vH4-59 } & \text { D } & \mathrm{n} & 4 & \mathrm{JH} 4\end{array}$

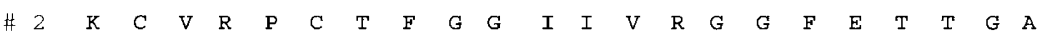

AAA TGT GTG AGG CCA TGT ACC TTT GGG GGA ATT ATC GTT CGT GGG GGG TTC GAG ACT ACI GGG GCC

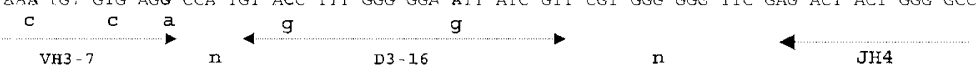

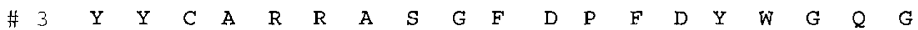

T'A2' T'AC T'GT GCG CGG CGA GCT AGT GGC TTC GAC CCC TTT GAC TAC 'I'GC GGC CAA GGA

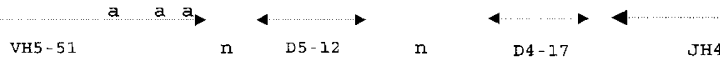

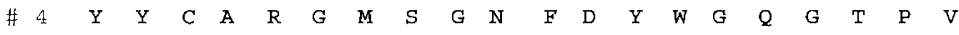

TA'T 'TAC IIGI GCG AGA GGA ATG AGT GGG AAC TTT GAC TAC TGG GGC CAG GGA ACC CCG GTC

$\stackrel{a}{\rightarrow}$

VH4 - 59

$\mathrm{n}$

$\longrightarrow \longrightarrow$

JH4

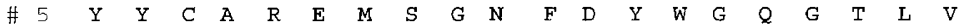

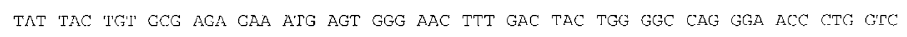
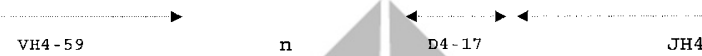

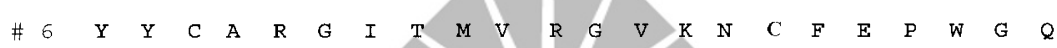

INT INA TC'I GCG AGA GGG ATT ACT ATG GTT CGG GGA UTC NAG AAC ITGC TT"T GAA CCC TGG GGC CAA

vH4.

VH4-59

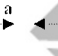

Figure 3.

CDR3 consensus sequences of gastric low-grade MALT lymphomas. $V_{H}$ PCR products were cloned and multiple clones sequenced. The deduced amino acid sequence of the consensus clone and the $\mathrm{V}_{H} D J_{H}$ joining sequences are shown. Nucleotide substitutions were identified by comparison of the consensus sequence with the published germline family sequence.

were lower than expected. These features are characteristic of antigen-selected antibodies that are under positive pressure to provide the "best fit" for antigen while retaining framework structure to provide the scaffolding for the antigen-contacting CDRs (Chang and Casali, 1994). On the other hand, two cases displayed R/S ratios in the CDRs lower than expected. A possible explanation for this feature may be selection by an autoantigen that usually provides negative selection pressure in CDRs to maintain autoantigen-binding affinity (Bahler et al, 1992; Friedman et al, 1991). Consistently the CDR3 translated sequences in these two cases showed homology to autoantibodies.

The length of CDR3 in all cases ranged from 7 to13 amino acids, in accord with reports (2 to 20 amino acids) by others in gastric low-grade MALT lymphomas (Bertoni et al, 1997; Du et al, 1996; Hallas et al, 1998; Qin et al, 1995; Thiede et al, 1998). Identical CDR3 with different $\mathrm{V}_{\mathrm{H}}$ sequences were found in two cases (4 and 5), suggesting the presence of a common selecting antigen. A similar process has been described in gastric MALT lymphomas by Bertoni et al (1997).

The high $\mathrm{R} / \mathrm{S}$ ratios in CDRs and low $\mathrm{R} / \mathrm{S}$ ratios in FRs or the homology with autoantibodies in addition to the presence of intraclonal diversification, confirm the positive selective pressure of an antigen that plays a fundamental role in the pathogenesis of this disease, especially during the low-grade stage (Greiner et al, 1994; Hussell et al, 1993).
Isotype switch and $\mathrm{V}_{\mathrm{H}}$ genes analysis in the six cases revealed several characteristics that suggest the existence of two distinct subsets of gastric low-grade MALT lymphoma. First, high levels of intraclonal diversification were found in two of three cases without isotype switch events. Noncommon mutations are indicative of ongoing somatic hypermutation (Bahler et al, 1991; Zelenetz et al, 1992) and allow the discrimination between germinal center B cells, which show ongoing mutations, and postgerminal center B cells, which do not (Kuppers et al, 1993).

Secondly, lower levels of common mutations $(2.4 \%$ on average) were found in cases without aberrant isotype switch events than in cases with such switch events $(7.8 \%$ on average). Thus one subset of gastric low-grade MALT lymphomas is characterized by $V_{H}$ intraclonal diversification, few common mutations, and no aberrant isotype switch, whereas the other subset is characterized by the absence of $\mathrm{V}_{\mathrm{H}}$ intraclonal diversification, many common mutations, and aberrant isotype switch. It is possible that the first subset originated from a germinal center environment and the second subset from a postgerminal center. Alternatively the initial transforming event might have occurred within the germinal center and additional maturation or transforming events blocked the mutational mechanism. Further studies are needed to determine whether these two subsets have prognostic 
relevance and will enable better evaluation of therapeutic modalities.

\section{Patients and Methods}

\section{Patients}

All cases met criteria considered to be diagnostic of low-grade MALT lymphomas according to the Revised European-American Classification of Lymphoid Neoplasms. Archival frozen tissue samples were obtained from patients at our institute.

\section{Immunohistochemistry}

The isotype of surface immunoglobulins was determined immunohistochemically on cryostat or paraffin sections using monoclonal antibodies specific for human Ig isotypes (DAKO, Glostrup, Denmark), according to the streptavidin-biotin method. Genomic DNA extraction and switch region analysis were performed as described (Nardini et al, 2000).

\section{PCR of $\mathrm{V}_{H}$ Regions and Cloning}

The $V_{H} D J_{H}$ region from each patient was amplified from genomic DNA $(1 \mu \mathrm{g})$ using a consensus forward primer, annealing in the framework 1 region [FR1: AGGTGCAGCTG(GC)(AT)G(GC)(AGT)GG], in combination with a joining heavy chain consensus primer [JH $\mathrm{JH}_{\mathrm{c}}$ ACCTGAGGAGACGGTGACC(AG)(GT)(GT)GT]. The PCR mixture contained $1 \times$ Taq buffer, $0.2 \mathrm{~mm}$ of each dNTP, $1 \mathrm{~mm}$ of $\mathrm{MgCl}_{2}, 10 \%$ dimethyl sulfoxide, 1 $\mathrm{U}$ of Taq polymerase (GIBCO, Paisley, Scotland), and $1 \mu \mathrm{M}$ of each primer in a final volume of $50 \mu \mathrm{l}$. PCR amplification consisted of an initial denaturation step at $94^{\circ} \mathrm{C}$ for 5 minutes, followed by 34 cycles at $94^{\circ} \mathrm{C}$ for 1 minute, $62^{\circ} \mathrm{C}$ for 1 minute, and $72^{\circ} \mathrm{C}$ for 2 minutes, with a final extension step at $72^{\circ} \mathrm{C}$ for 10 minutes. To verify monoclonality, PCR products were analyzed on an $8 \%$ acrylamide gel. Rearranged $V_{H} D J_{H}$ sequences of cases 5 and 6 were amplified using a semi-nested strategy and different primer pairs: FR2 [5' TGG(AG)TCCG(AC)CAG(GC)C(CT)(CT)C(AGCT)GG $\left.3^{\prime}\right]$, annealing in the framework 2 region, and $\mathrm{LJH}\left[5^{\prime}\right.$ TGAGGAGACGGTGACC 3'], annealing in the joining region. The first round of PCR was performed in $50 \mu \mathrm{l}$, containing $200 \mu \mathrm{M}$ of each dNTP, $4.5 \mathrm{mM} \mathrm{MgCl}_{2}, 0.7$ $\mu \mathrm{M}$ primers, and $1 \times$ Taq buffer. Hot-start was performed by the addition of $0.25 \mathrm{U}$ of Taq polymerase (GIBCO) after 7 minutes at $95^{\circ} \mathrm{C}$. PCR consisted of 30 cycles at $93^{\circ} \mathrm{C}$ for 45 seconds, $50^{\circ} \mathrm{C}$ for 45 seconds, and $72^{\circ} \mathrm{C}$ for 1 minute followed by a final extension step at $72^{\circ} \mathrm{C}$ for 5 minutes. One microliter of the first amplification was used for second-round PCR under identical conditions, except the VLJH [5' GTGACCAGGGT(AGCT)CCTTGGCCCCAG 3'] primer was substituted for the $\mathrm{LJH}$ primer, $\mathrm{MgCl}_{2}$ concentration was decreased to $2.5 \mathrm{~mm}$, and 20 cycles were performed. Bands corresponding to $\mathrm{V}_{\mathrm{H}}$ genes were isolated from a $2 \%$ low-melting agarose gel, and the DNAs were purified using a Jetquick Kit (Genomed $\mathrm{GmbH}$, Bad Oeynhausen, Germany). Approximately
20 ng of purified DNA was cloned using the TOPO TA Cloning Kit (Invitrogen, San Diego, California). Both strands of the inserts were sequenced from three or more randomly selected bacterial colonies using an $\mathrm{ABI}$ sequencer to obtain the sequence of the dominant clone (consensus sequence).

\section{Mutational Analysis of $\mathrm{V}_{H}$ Genes}

The $V_{H}$ sequence from FR1 to FR3 of each clone was analyzed using the immunoglobulin Blast database and compared with the germline sequence with the highest homology to identify mutations. Common (somatic) mutations were defined as a nucleotide substitution shared among all clones of a given $\mathrm{V}_{\mathrm{H}}$; noncommon (intraclonal) mutations were defined as a nucleotide substitution present in some but not all clones of a given $\mathrm{V}_{\mathrm{H}}$. A stretch of seven consecutive nucleotide matches was considered indicative of specific D gene usage. Expected R/S for CDRs and FRs were calculated according to the model of Chang and Casali (1994). Homology to published germline clones was searched at both the nucleotide and protein levels. Statistical analysis were performed with the $t$ test.

\section{Acknowledgements}

We thank Miss Laura Ghedini for technical help and Miss Laura Mameli for manuscript preparation.

\section{References}

Bahler DW, Campbell MJ, Hart S, Miller RA, Levy S, and Levy $R$ (1991). $\lg V_{H}$ gene expression among human follicular lymphomas. Blood 78:1561-1568.

Bahler DW, Zelenetz AD, Chen TT, and Levy R (1992). Antigen selection in human lymphomagenesis. Cancer Res 52:5547s-5551s.

Bayerdorffer E, Neubauer A, Rudolph B, Thiede C, Lehn N, Eidt S, and Stolte M (1995). Regression of primary gastric lymphoma of mucosa-associated lymphoid tissue type after cure of Helicobacter pylori infection. MALT Lymphoma Study Group. Lancet 345:1591-1594.

Berek C, Berger A, and Apel M (1991). Maturation of the immune response in germinal centers. Cell 67:1121-1129.

Bertoni F, Cazzaniga G, Bosshard G, Roggero E, Barbazza R, de Boni M, Capella C, Pedrinis E, Cavalli F, Biondi A, and Zucca E (1997). Immunoglobulin heavy chain diversity genes rearrangement pattern indicates that MALT-type gastric lymphoma $B$ cells have undergone an antigen selection process. $\mathrm{Br} \mathrm{J}$ Haematol 97:830-836.

Chang B and Casali P (1994). The CDR1 sequences of a major proportion of human germline $\lg V_{H}$ genes are inherently susceptible to amino acid replacement. Immunol Today 15:367-373.

Du M, Diss TC, Xu C, Peng H, Isaacson PG, and Pan L (1996). Ongoing mutation in MALT lymphoma immunoglobulin gene suggests that antigen stimulation plays a role in the clonal expansion. Leukemia 10:1190-1197.

Friedman DF, Cho EA, Goldman J, Carmack CE, Besa EC, Hardy RR, and Silberstein LE (1991). The role of clonal 
selection in the pathogenesis of an autoreactive human $B$ cell lymphoma. J Exp Med 174:525-537.

Greiner A, Marx A, Heesemann J, Leebmann J, Schmausser $B$, and Muller-Hermelink HK (1994). Idiotype identity in a MALT-type lymphoma and B cells in Helicobacter pylori associated chronic gastritis. Lab Invest 70:572-578.

Hallas C, Greiner A, Peters K, Konrad H, and MullerHermelink HK (1998). Immunoglobulin $V_{H}$ genes of highgrade mucosa-associated lymphoid tissue lymphomas show a high load of somatic mutations and evidence of antigendependent affinity maturation. Lab Invest 78:277-287.

Hummel M, Tamaru J, Kalvelage B, and Stein H (1994). Mantle cell (previously centrocytic) lymphomas express $V_{H}$ genes with no or very little somatic mutations like the physiologic cells of the follicle mantle. Blood 84:403-407.

Hussell T, Isaacson PG, Crabtree JE, Dogan A, and Spencer J (1993). Immunoglobulin specificity of low-grade B cell gastrointestinal lymphoma of mucosa-associated lymphoid tissue (MALT) type. Am J Pathol 142:285-292.

Kuppers R, Klein U, Hansmann ML, and Rajewsky K (1999). Cellular origin of human B cell lymphomas. $\mathrm{N}$ Engl $\mathrm{J}$ Med 341:1520-1529.

Kuppers R, Zhao M, Hansmann ML, and Rajewsky K (1993). Tracing B cell development in human germinal centres by molecular analysis of single cells picked from histological sections. EMBO J 12:4955-4967.

Levy R, Levy S, Cleary ML, Carroll W, Kon S, Bird J, and Sklar $\mathrm{J}$ (1987). Somatic mutation in human B cell tumors. Immunol Rev 96:43-58.

Matolcsy A, Casali P, Nador RG, Liu YF, and Knowles DM (1997). Molecular characterization of IgA- and/or lgGswitched chronic lymphocytic leukemia B cells. Blood 89: 1732-1739.

Miklos JA, Swerdlow SH, and Bahler DW (2000). Salivary gland mucosa-associated lymphoid tissue lymphoma immunoglobulin $\mathrm{V}(\mathrm{H})$ genes show frequent use of $\mathrm{V} 1-69$ with distinctive CDR3 features. Blood 95:3878-3884.

Montalban C, Manzanal A, Boixeda D, Redondo C, Alvarez I, Calleja JL, and Bellas C (1997). Helicobacter pylori eradication for the treatment of gastric low-grade MALT lymphoma: follow-up together with sequential molecular studies. Ann Oncol 8:37-39.

Nakamura S, Aoyagi K, Furuse M, Suekane H, Matsumoto T, Yao T, Sakai Y, Fuchigami T, Yamamoto I, Tsuneyoshi M, and Fujishima M (1998). B cell monoclonality precedes the development of gastric MALT lymphoma in Helicobacter pylori-associated chronic gastritis. Am J Pathol 152:12711279.

Nardini E, Aiello A, Giardini R, Colnaghi MI, Ménard S, and Balsari A (2000). Detection of aberrant isotype switch recombination in low-grade and high grade gastric MALT lymphomas. Blood 95:1032-1038.
Qin Y, Greiner A, Hallas C, Haedicke W, and MüllerHermelink H-K (1997). Intraclonal offspring expansion of gastric low-grade MALT-type lymphoma: evidence for the role of antigen-driven high-affinity mutation in lymphomagenesis. Lab Invest 76:477-485.

Qin Y, Greiner A, Trunk MJ, Schmausser B, Ott MM, and Muller-Hermelink HK (1995). Somatic hypermutation in lowgrade mucosa-associated lymphoid tissue-type B cell lymphoma. Blood 86:3528-3534.

Rajewsky K (1996). Clonal selection and learning in the antibody system. Nature 381:751-758.

Rassenti LZ and Kipps TJ (1997). Lack of allelic exclusion in B cell chronic lymphocytic leukemia. J Exp Med 185:14351445.

Roggero E, Zucca E, Pinotti G, Pascarella A, Capella C, Savio A, Pedrinis E, Paterlini A, Venco A, and Cavalli F (1995). Eradication of Helicobacter pylori infection in primary lowgrade gastric lymphoma of mucosa-associated lymphoid tissue. Ann Intern Med 122:767-769.

Steinbach G, Ford R, Glober G, Sample D, Hagemeister FB, Lynch PM, McLaughlin PW, Rodriguez MA, Romaguera JE, Sarris AH, Younes A, Luthra R, Manning JT, Johnson CM, Lahoti S, Shen Y, Lee JE, Winn RJ, Genta RM, Graham DY, and Cabanillas FF (1999). Antibiotic treatment of gastric lymphoma of mucosa-associated lymphoid tissue: An uncontrolled trial. Ann Intern Med 131:88-95.

Thiede C, Alpen B, Morgner A, Schmidt M, Ritter M, Ehninger G, Stolte M, Bayerdorffer E, and Neubauer A (1998). Ongoing somatic mutations and clonal expansions after cure of Helicobacter pylori infection in gastric mucosa-associated lymphoid tissue B cell lymphoma. J Clin Oncol 16:3822-3831.

Wotherspoon AC, Ortiz-Hidalgo C, Falzon MR, and Isaacson PG (1991). Helicobacter pylori-associated gastritis and primary B cell gastric lymphoma. Lancet 338:1175-1176.

Yumoto N, Kurosu K, Furukawa M, and Mikata A (1999). CDR3 sequences of MALT lymphoma show homology with those of autoreactive B cell lines. Jpn J Cancer Res 90:849857.

Zelenetz AD, Chen TT, and Levy R (1992). Clonal expansion in follicular lymphoma occurs subsequent to antigenic selection. J Exp Med 176:1137-1148.

Zucca E, Bertoni F, Roggero E, Bosshard G, Cazzaniga G, Pedrinis E, Biondi A, and Cavalli F (1998). Molecular analysis of the progression from Helicobacter pylori-associated chronic gastritis to mucosa-associated lymphoid-tissue lymphoma of the stomach. N Engl J Med 338:804-810. 